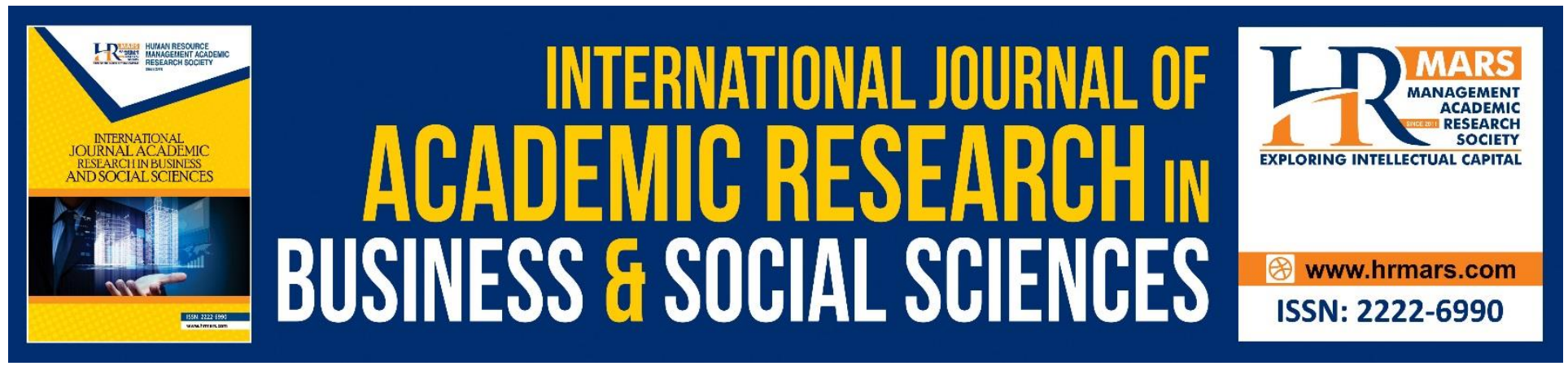

\title{
Review on Police Uniform Perception
}

\author{
Mohd Razali Alias, Arsiah Bahron
}

To Link this Article: http://dx.doi.org/10.6007/IJARBSS/v9-i6/6035

DOI: $10.6007 /$ IJARBSS/v9-i6/6035

Received: 18 April 2019, Revised: 19 May 2019, Accepted: 07 June 2019

Published Online: 30 June 2019

In-Text Citation: (Alias \& Bahron, 2019)

To Cite this Article: Alias, M. R., \& Bahron, A. (2019). Review on Police Uniform Perception. International Journal of Academic Research in Business and Social Sciences, 9(6), 808-816.

\section{Copyright: (C) 2019 The Author(s)}

Published by Human Resource Management Academic Research Society (www.hrmars.com)

This article is published under the Creative Commons Attribution (CC BY 4.0) license. Anyone may reproduce, distribute, translate and create derivative works of this article (for both commercial and non-commercial purposes), subject to full attribution to the original publication and authors. The full terms of this license may be seen

at: http://creativecommons.org/licences/by/4.0/legalcode

Vol. 9, No. 6, 2019, Pg. $808-816$

http://hrmars.com/index.php/pages/detail/IJARBSS

JOURNAL HOMEPAGE

Full Terms \& Conditions of access and use can be found at http://hrmars.com/index.php/pages/detail/publication-ethics 


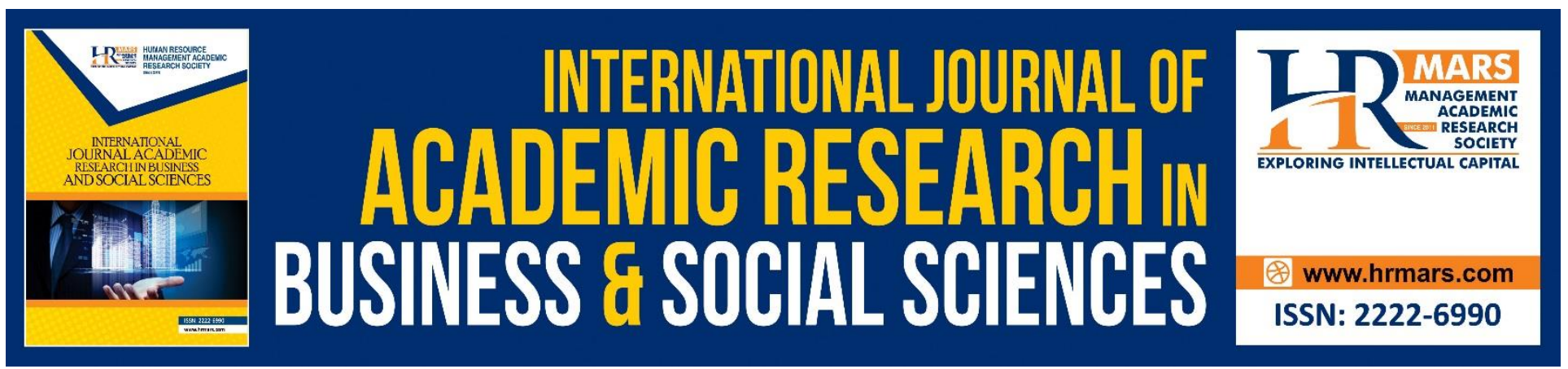

\title{
Review on Police Uniform Perception
}

\author{
Mohd Razali Alias, Arsiah Bahron \\ Faculty of Business, Economics and Accountancy, Universiti Malaysia Sabah, 88400 Kota Kinabalu, \\ Malaysia
}

\begin{abstract}
This paper intends to review studies on the perception of police uniform concerning colour and the components of the uniform. Although the police uniforms are perceived to be the unifying factor or element within the policing sector there have been studies, which suggest that police uniform can influence a negative or positive perception. Most of the past and recent studies have demonstrated that colour and other components of police uniform significantly influence perception in regards to police uniforms. Coherently, the dark and grey police uniforms have been noted to depict aggressiveness or negativity, which in turn, perceptions. Besides, multiple uniform components such as hats, gloves, vests, baton, and sunglasses have been observed to have a significant influence on perception in regards to police officers.
\end{abstract}

Keywords: Uniform, Perception, Police Officer, Colour, Uniform Component

\section{Introduction}

According to Wickramasinghe et al. (2018) policing deals with sustained and relentless work stress associated with danger and human miseries, and is often cited as one of the most vulnerable categories of human service profession for a mental health problem. Now, police officer facing the new threat which citizen confused the image which other enforcement agencies use almost the same (such as uniform wear and their asset).

The police uniform is perceived to be among the most important tools or equipment used by the police, which means that the uniform acts as a symbolic attribute that demonstrates the membership of the officer within the police department (Simpson, 2018). Uniforms play significant roles within a given organization in specific levels such as strategic level (Heide and Gronhaug 2009; Daniel, 1996), and operational level (Martínez-Tomé, Vera, \& Murcia, 2000).

The significance of the uniform has been demonstrated across multiple industries, especially, in the hospitality and service sectors. Specifically, Nelson and Bowen (2000); (Yeh, Tu, Chuang \& Lin, 2013) appreciated the significance of uniform in the hospitality industry where the latter stress the importance of uniforms as the component of establishing the brand in the hospitality sector. Such observations regarding the impact of uniform in the hospitality sector have been cemented by Karch \& Peters (2017) who suggested that uniforms play an important role in improving performance and experiences in the service sector. Clothing is perceived to be a powerful instrument in the formation 
of perceptions; also, cloths serve as the "mental shortcut" in determining an individual's social status, legitimacy, occupation, and authoritativeness (Johnson, Schofield \& Yurchisin, 2002).

Previous studies conducted by various scholars have illustrated that motorists are typically unlikely to make a wrong turn in an intersection when the driver "spot" a person fitted in police-style uniform. The specific colours or details that are entailed in a police uniform have been observed to influence the perception of an individual. For instance, a study by Obasi (2018) demonstrated how police body-cams, which are part of contemporary police uniforms, influenced the perception of the police officer in regards to their years of service. This demonstrates how the uniform can influence police perception.

Simpson (2018) in his study, deduced that various components, which comprise of police uniforms such as the baton, sunglasses, vests, and hat have a significant impact on the perception of police uniform. Ideally, what an individual wears tends to influence to an extent- their individualistic perception. Coherently, clothing has played an imperative function of determining an individual's gender, social status, occupation, and group association among others Daniel, Johnson \& Miller (1996). Typically, what a person's where can elicit different feelings or perceptions of his or her immediate impression or coherent subconsciousness. Moreover, subconscious factors such as trustworthiness, intelligence, honesty, and confidence tend to influence significantly the perception of an individual; however, cloths or uniforms have a "trigger-effect" regarding the above mentioned subconscious factors in regards to influencing perception.

Similarly, a study conducted by Rebecca Walther (2018) on police public perception identified the appearance of a police officer, in this case, their uniform can elicit or influence the perception of a police officer. Additionally, studies by Hannover and Kuehnen (2002) suggest that clothing can alter the self-perception and mood of an individual. Moreover, similar studies undertaken by Balkin and Houlden (1983) deduced that the uniforms of police officers conveyed impressions of reliability, competence, and intelligence this is in cohorts with other past studies that have found that police uniforms can influence perception among the police or the public at large.

Shao, Baker \& Wagner (2004); and Rafaeli (1993) on their studies relating to employee uniform and job satisfaction noted that uniforms among the employee play a crucial role in influencing service expectations, which in turn, can influence perception. Such observation demonstrates that the police uniform can influence the perception of the police officer or the public in general; which is in coherence with this article that has been geared towards examining the uniforms perception among police officers serving in the Royal Malaysia Police.

\section{Police Uniform Perception}

The uniform worn by police officers can evoke or elicit different emotions or perspectives such as legitimacy, status, and group membership depending on an individual (Simpson, 2017) or influence perspective of impression (Johnson et al., 2002; Nickels, 2008). Coherently, different studies have been able to isolate multiple factors, which can be attributed as influencing factors or construct towards uniform police perception such as colour (Johnson 2005). These factors can be assumed to influence or impact a majority of police departments globally, which include the Royal Malaysia Police. This is primarily because most of the police departments globally operate on almost similar principles and frameworks. 
The Malaysian police departments have been categorized into multiple police units and agencies, among which each policing unit ear a different type of police uniform for ease of being identified. For instance, since 2013 the Malaysian immigration police have been wearing black uniforms a change from the white and dark blue uniforms; typically, most of the royal Malaysia police officer wear dark or dark blue uniforms.

\section{Perception of Colour}

Ideally, most scholars have been able to deduce studies, which have demonstrated that coloursespecially- dark colours tend to have a significant impact on the perception of an individual. A study conducted by Johnson (2005) discovered that colours in general influence an individual's impressions and moods. In essence, the colour of the uniform worn by a police officer can influence perception in the long run. For instance, the colour red is associated with stimulation and excitement blue with comfort and security while black or dark with evil (Simpson, 2018). Notably, these findings have been observed to share similar observational consistencies in similar subject matter across, Europe, Asia, and Africa (Adams \& Osgood, 1973; Williams et al., 1970).

Henceforth, the recently introduced police constable uniforms for the Malaysian Royal Police in 2008 can be observed to have generally dark shade. Therefore, these dark uniforms can influence the perception of the Royal Malaysian Police negatively since according to past research black or dark colour can influence negative perceptions. Similarly, studies conducted by Frank and Giloch (1980) demonstrated that hockey and football players wearing dark blue or black uniforms were perceived negatively by the referees compared to the other players who wore lighter uniforms. Therefore, it can be noted that generally, most of the police units within the Royal Malaysia Police who wear dark or grey attires are more likely to be perceived more negatively compared to their counterparts who wear bright and "attractive" coloured uniforms.

Generally, the Royal Malaysia Police wear dark uniforms, which give them a sense of aggressiveness and "respect" from the general public, however, some units within the police department such as the traffic police wear white shirts which according to researchers create a positive perception from the public. In contrast, elite units within the Royal Malaysia Police such as the Special Action Unit (UTK) wear black uniforms, which evoke a sense of prowess, aggressiveness, and "fear" among the royal Malaysia police officers. This sense of "aggressiveness" among the officers illicit a perception that the royal Malaysia police are "the best" police force thus demonstrating how uniform influences perception in respect to the Royal Malaysia Police.

\section{Perception of the Uniform Components}

The uniforms worn by contemporary global police forces have been designed and equipped in various gadgets or cloths depending on the nature and scope of their operations (Parks, 2003). The modern police officer uniform entails several components, which have been observed to influence perception in respect to police uniforms. Moreover, the contemporary policing departments are beginning to incorporate the military-style form of equipment and uniforms as noted by (Paul \& Birzer, 2004). Some of these features entailed in the police uniforms as identified by scholars include sunglasses, baton, vests, gloves, and hats. Coherently, scholars such as Johnson et al., 2014; Simpson (2014), Dempesey et al. (2013), and LaTourrette (2010) have provided extensive literature on the influence 
of the abovementioned components regarding police uniforms. Nonetheless, most of these "components" have been embedded as part of the Royal Malaysia Police uniform especially among the elite units and specialized departments within the force. The police body amour or vests are usually worn to protect the police officer from projectiles of any kind and bullets injuries (LaTourrette, 2010). Furthermore, the advancement in technology has facilitated the introduction relating to vest functionality such as the load-bearing vest for carrying extra ammunition, and high visibility fluorescent vest for traffic officers (Barker, Black \& Cloud, 2010).

Conversely, some researchers have investigated and deduced that vests are increasingly restricting police officer's movement and mobility (Dempesey et al., 2013). Ideally, the life-protective functions of the modernized police vest are reserved for internal and non-visible functions to protect life; however, the accompanying equipment may have the "weapon focus' effect. The accumulation of equipment such as ammunitions, knives, and body-cam may create a scenario that can be perceived to aggressiveness and strength. Such perception, which can be associated with police vests (uniform) demonstrates how police officers are perceived. In contrast, the high-visibility fluorescent vests primary function is to improve a police officer vest barrier, especially, in traffic.

Notably, multiple scholars have deduced that darker police vest or uniforms tend to negatively impact the behaviour and perception of uniformed-bearers. For instance, Johnson (2005) deduced that black or dark uniforms tend to generate a negative perception concerning the police. Notably, the high-visibility uniform vests are often worn by a police officer in non-threatening circumstances such as in zebra crossing junction and school bus stops among other places. Coherently, Simpson, (2018) suggested that a police officer wearing high-visibility vest uniforms are less perceived as aggressive and friendly. Such observations demonstrate uniform perception among police officers.

The glove has increasingly become popular among the police forces around the globe, more specifically, within the police elite units. The emergence of new threats has given rise to the creation of specialized police units (special force), which are specially trained for specific threats (Johansen, 2015). However, there are no studies, which have been dedicated to examining the utility of gloves within the policing context; nonetheless, policing experts laments on their benefits and usefulness. For instance, most security experts state that gloves protect police officers from physical contaminations or protection from injuries during operations; most importantly, to preserve evidence in a crime scene (Lin, Luiselli, Gilligan \& Dacosta, 2012). Therefore, the gloves are worn by police officers as part of the recommended uniform- mostly black. Moreover, Simpson (2018) suggest that in lieu of above-discussed points the wearing of black gloves by the police officer may create a perception that a police officer is armed or anticipating to engaged in a risky operation. This means that the gloves may portray the perceived aggression of the police officer. The glove, which is part of the police uniform, has been observed to influence the perception of police officers uniforms.

Similarly, the police batons are perceived to among the most "oldest" tools used by a modernized police force. Coherently, the functionally and usage of the baton in the contemporary police force are now ubiquitous their physical attributes are still perceived to be varied depending on the police force. The police batons exist in different sizes depending on the usage and are made from a variety of materials such as iron, wood, and aluminum among others (Simpson, 2018). Moreover, since there are no previous studies or literature that explain the correlation between batons and 
uniform perception in regards to the police officer (Gervias, Baudin, Cruikshank \& Dahlstedt, 1998). However, from the impact perspective, as elaborated by Gervias et al. (1998) about size and force exerted by the baton, it is practical to suggest that the presence of a baton will create a potential perception in respect to aggression (Simpson, 2018). Therefore, the police baton, which is part of the police uniform, can be observed to influence perception among police officers.

Like batons, sunglasses have been utilized by security agencies for decades as part of the police uniforms. Today, Royal Malaysia Police Special units such as the Special Action Unit encompass sunglasses as part of their tactical uniforms. The presence of the sunglasses has been observed to evoke negative perception. For instance, a study undertaken by Boyanowsky and Griffiths (1982) deduced that the public perceived negatively uniformed police wearing sunglasses compared to those who have no sunglasses. Such findings demonstrate how sunglasses- which are part of police uniform- can influence perception in respect to the police uniform. Moreover, Simpson (2018) suggest that police officer utilize headwear to intensify their authority and presence within the public domain. Notably, different police hats have been designed to cater for the different needs depending on the circumstance such as ceremony or operations. There are contrasting findings from different authors regarding the perception of hats as police uniforms. In contrast, Johnson et al. (2015) concluded that there are no induced perceptions of a police officer based on their police harts. Coherently, Simpson (2018) suggest the dark colour of the baseball hart that forms part of the police uniform, like those of the Royal Malaysia Police, evoke a sense of authority or aggression, which may influence the perception of the latter in regards to the police uniform.

\section{Methodology}

The study participants will include police officers serving in the Malaysian Royal Police Force. A pilot study will be the first conduct to probe whether all questionnaire items are clear and shall not confuse the study participants when responding. The sample population for the study includes 100 police officer from different hierarchical levels in the force that will randomly be selected via a random sampling technique. The pilot study will also help the researcher to identify the meaningfulness of the language used from the feedback from the pilot study participants. However, the data obtained from the pilot study will not be included in the final data analysis. Base on the feedback from the pilot study, the researcher will seek to improve the readability and clarity of the questionnaire items to ensure that the survey responses are accurate. From the pilot survey's feedback, the researcher will reword or delete troublesome language (if any).

Participation in the study will be voluntary where the target respondents will be provided with a letter of informed consent that will be attached on the first page of the questionnaire with explanation of the aim of the study, the estimated time for completion of the questionnaire and a promise to ensure confidentiality and privacy of the gathered data. The study will collect demographic data of the participants including the seniority, job level, and position, department in the organization among other items. To maximize the response rates, the researcher will provide both paper-and-pencil formats as well as the online format to the police officers. The questionnaires targeted 100 police officers in the survey. Returning questionnaires will be manually checked for completeness. 


\section{Conclusion}

This research review has detailed literature which has been geared towards examining the impact of uniform on perception concerning police officers. However, there are notable concerns, which have been observed to influence perception in a conflicting manner about the police officer Royal Malaysia Police. In conclusion, there several imperative avenues for future studies to explore and research the subject matter since very few researchers have analyzed the influence of police uniforms, and how they influence perception. There is a growing interest in examining or studying the influence or perception of police uniform from either the public or the police perspective. Moreover, this review has provided detailed literature on some of the crucial factors that have been observed to influence uniform perception among police officer by incorporating studies undertaken by other researchers locally and globally.

\section{Contextual Framework}

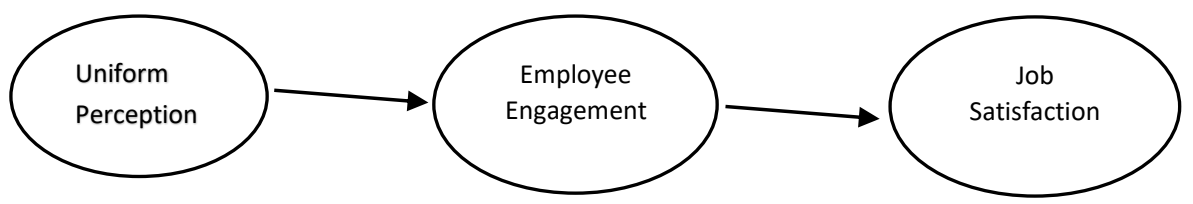

Figure 1: Conceptual Framework on Uniform Perception of the Royal Malaysia Police

\section{Recommendations}

Several recommendations are put forward from this research thus:

1. Use information from this research (uniform perception) to develop a detailed plan of how to increase confidence among police officers towards job satisfaction in the Royal Malaysia Police.

2. Do the more exhaustive examination of uniform perception to determine best practices for the Royal Malaysia Police.

3. Conduct pilot projects to measure uniform perception in the Royal Malaysian Police Force

\section{Corresponding Author}

Mohd Razali Alias, Faculty of Business, Economics and Accountancy, Universiti Malaysia Sabah, 88400 Kota Kinabalu, Malaysia, email: adieyyusuf@outlook.my

\section{References}

Adams, F. M., \& Osgood, C. E. (1973). A cross-cultural study of the affective meanings of colour. Journal of cross-cultural psychology, 4(2), 135-136.

Balkin, S., \& Houlden, P. (1983). Reducing fear of crime through occupational presence. Criminal Justice and Behavior, 10, 13-33. 
Barker, J., Black, C., \& Cloud, R. (2010). Comfort comparison of ballistic vest panels for police officers. Journal of Textile and Apparel, Technology and Management, 6(3).

Boyanowsky, E. O., \& Griffiths, C. T. (1982). Weapons and Eye Contact as Investigators or Inhibitors of Aggressive Arousal in Police-Citizen Interaction 1. Journal of Applied Social Psycology, 12(5), 398-407.

Daniel K, Johnson LW, Miller KE (1996) Dimensions of uniform perceptions among service providers. The Journal of Services Marketing 10: 42-56.

Daniel, K. (1996). Dimensions of uniform perceptions among service providers. Journal of Services Marketing, 10(2), 42-56.

Dempsey, P. C., Handcock, P. J., \& Rehrer, N. J. (2013). Impact of police body armour and equipment on mobility. Applied ergonomics, 44(6), 957-961.

Frank M. G., Gilovich, T. (1988). The dark side of self and social perception: Black uniforms and aggression in professional sports. Journal of Personality and Social Psychology, 54, 74-85.

Gervais, P., Baudin, P., Cruikshank, B., \& Dahlstedt, D. L. (1998). Comparative analysis between police batons. Forensic Science International, 91(1), 7-17.

Hannover, B., \& Kuehnen, U. (2002). The clothing makes the self via knowledge activation.Journal of Applied Social Psychology, 32, 2513-2525.

Heide M, Gronhaug K (2009) Key factors in guests' perception of hotel atmosphere. Cornell Hospitality Quarterly 50: 29-43.

Johansen, I. (2015). Special operations forces-a weapon of choice for future operations?. In International Military Operations in the 21st Century (pp. 113-131). Routledge.

Johnson, K. P., Schofield, N. A., \& Yurchisin, J. (2002). Appearance and dress as a source of information: A qualitative approach to data collection. Clothing and Textiles Research Journal, 20, 125-137.

Johnson, R. R. (2005). Police uniform colour and citizen impression formation. Journal of police and criminal psychology, 20(2), 58-66.

Johnson, R. R., Plecas, D., Anderson, S., \& Dolan, H. (2015). No hat or tie required: examining minor changes to the police uniform. Journal of Police and Criminal Psychology, 30(3), 158-165.

Karch, G. E., \& Peters, M. (2017). The Impact of Employee Uniforms on Job Satisfaction in the Hospitality Industry. Journal of Hotel and Business Management, 6(1), 1-6.

LaTourrette, T. (2010). The life-saving effectiveness of body armor for police officers. Journal of occupational and environmental hygiene, 7(10), 557-562.

Lin, T., Luiselli, J. K., Gilligan, K., \& Dacosta, S. (2012). Preventing injury from child aggression: A singlecase evaluation of the effects of staff-worn protective equipment. Developmental neurorehabilitation, 15(4), 298-303.

Martínez-Tomé, M., Vera, A. M., \& Murcia, M. A. (2000). Improving the control of food production in catering establishments with particular reference to the safety of salads. Food Control, 11(6), 437-445.

Nelson, K., \& Bowen, J. (2000). The effect of employee uniforms on employee satisfaction. Cornell Hotel and Restaurant Administration Quarterly, 41(2), 86-95.

Obasi, J. E. (2018). Police Officers' Perceptions of Body-Worn Camera Technology.

Parks, W. H. (2003). Special Forces' Wear of Non-Standard Uniforms. Chi. J. Int'I L., 4, 493. 
Paul, J., \& Birzer, M. L. (2004). Images of power: An analysis of the militarization of police uniforms and messages of service. Free Inquiry in Creative Sociology, 32(2), 121-128.

Rafaeli, A. (1993). Dress and Behaviour of customer contact employees: A framework for analysis. Advance in services marketing and management, 2, 175-211.

Rebecca, W. (2018, May 14). Public Perception. Retrieved from https://policeandsecuritynews.com/2018/05/14/2196/ (FOR REBECCA WALTER, Publication).

Shao CY, Baker J, Wagner JA (2004). The effects of appropriateness of service contact personnel dress on customer expectations of service quality and purchase intention. The moderating influences of involvement and gender. Journal of Business Research 57: 1164-1176.

Simpson, R. (2017). The Police Officer Perception Project (POPP): An experimental evaluation of factors that impact perceptions of the police. Journal of Experimental Criminology, 13(3), 393415.

Simpson, R. (2018). Officer Appearance and Perceptions of Police: Accoutrements as Signals of Intent. Policing: A Journal of Policy and Practice.

Wickramasinghe, N. D., \& Wijesinghe, P. R. (2018). Burnout subtypes and associated factors among police officers in Sri langka : A cross-sectional study. Journal of Forensic and Legal Medicine.58: 192-198

Williams, J. E., \& McMurtry, C. A. (1970). Colour connotations among Caucasian seventh graders and college students. Perceptual and Motor Skills, 30(3), 707-713.

Yeh, R., Tu, Y. T., Chuang, N. K., Lin, M. J. J., \& Lin, H. J. T. (2013). Hotel employees' uniform and their self-perceptions in Southern California. Tourism Management Perspectives, 6, 79-81. 